\title{
Öğretmenler Arasında Mesleki İşbirliğine Yönelik Tutum Ölçeğinin Geliştirilmesi
}

\author{
Kürşad YILMAZ ${ }^{1}$ ve Mustafa ÇELİK ${ }^{2}$
}

Öz

$\mathrm{Bu}$ araştırmanın amacı, öğretmenler arasında mesleki işbirliği konusunda öğretmenlerin tutumlarını belirlemede kullanılabilecek bir ölçek geliştirmektir. Araştırmada ölçeğin yap1 geçerliğinin belirlenmesi için yapılan açımlayıcı faktör analizi (AFA) ve doğrulayıcı faktör analizi (DFA) için iki farklı gruptan veri toplanmıştır. Birinci çalışma grubunda okulöncesi eğitim, ilkokul, ortaokul ve lise öğretmenlerinden oluşan 273 kişi, ikinci çalışma grubunda ise 164 kişi bulunmaktadır. AFA sonucunda ölçeğin tek faktörlü ve 13 maddeden oluşan bir yapıda olduğu belirlenmiştir. Bu tek faktörün açıkladığı varyans oranı \% 41.10'dur. Bu yapı DFA ile doğrulanmıştır. DFA ile hesaplanan uyum iyiliği indeksleri şöyledir: $\chi^{2} / \mathrm{sd}=1,475, \mathrm{GFI}=.952$, AGFI=.933, IFI=.972, RMR=.025, CFI=.971, NFI=.917, RMSEA =.042. Ölçeğin Cronbach's Alfa iç tutarlılık katsayısı .87'dir. Sonuç olarak, öğretmenler arası mesleki işbirliği konusunda öğretmenlerin tutumlarını belirlemede kullanılabilecek geçerli ve güvenilir bir veri toplama aracı geliştirilmiştir.

Anahtar Kelimeler: Öğretmenler Arası Mesleki İşbirliği, Öğretmen Tutumu, Ölçek

\section{Development of Scale of Attitude towards Professional Collaboration among Teachers}

\section{Abstract}

The purpose of this study is to develop a scale which can be used to determine the attitude of teachers to professional cooperation between instructors. Data for the study were collected from two different groups for exploratory factor analysis (AFA) and confirmatory factor analysis (CFA) to determine the reliability of the scale. The first study group consisted of 273 people. They were teachers of preschool education, primary school, high school while in the second study group there were 164 people. As a result, AFA found that the scale has a one-factor structure and consists of 13 points. The dispersion coefficient to this single factor is $41.10 \%$. This structure has been verified with DFA. Correspondence reliability indicators calculated by DFA as following: $\chi 2 /$ sd $=1475$, GFI = $0.952, \mathrm{AGFI}=0.933, \mathrm{IFI}=0.972, \mathrm{RMR}=0.025, \mathrm{CFI}=0.971, \mathrm{NFI}=0.917, \mathrm{RMSEA}=0.042$. The coefficient of internal consistency according to Cronbach's scale is 0.87 . As a result a reliable data collecting tool has been developed to determine teachers' attitudes towards professional collaboration between teachers.

Key Words: Professional Collaboration Between Teachers, Teacher Attitude, Scale

\section{Atıf İçin / Please Cite As:}

Yılmaz, K. ve Çelik, M. (2020). Öğretmenler arasında mesleki işbirliğine yönelik tutum ölçeğinin geliştirilmesi. Manas Sosyal Araștirmalar Dergisi, 9(2), 731-740.

Geliş Tarihi / Received Date: 01.07.2019

Kabul Tarihi / Accepted Date: 25.08.2019

\footnotetext{
${ }^{1}$ Prof. Dr. - Kütahya Dumlupınar Üniversitesi, Eğitim Fakültesi, kursadyilmaz@gmail.com ORCID: 0000-0002-3705-5094

2 Arş. Gör. - Kütahya Dumlupınar Üniversitesi, Eğitim Fakültesi, mcelik_83@yahoo.com ORCID: 0000-0001-6825-315X
} 


\section{Giriş}

Öğretmenlik mesleği, sınıf ve benzeri ortamlarda diğer kişilerden yalıtılmış olarak icra edildiğinden geleneksel olarak yalıtılmış bir meslek olduğu ileri sürülebilir. Ancak işin özü düşünüldüğünde öğretmenlerin mesleki gelişimleri ile ilgili en güçlü destek kaynaklarının meslektaşları olduğu da unutulmamalıdır. Öğretmenlerin birbirleri ile iletişim halinde olması ve deneyimlerini paylaşması bu sürecin en önemli noktasıdır. Bu bağlamda son ylllarda öğretmenliğin yalıtılmış bir şekilde değil, işbirliği içerisinde yapılması gerektiğinden bahsedilmekte ve öğretmenlerin mesleki konularda işbirliği yapmasının okul ve eğitim üzerinde birçok olumlu etkisinin olduğu belirtilmektedir. $\mathrm{Bu}$ olumlu sonuçlardan en önemlisi öğrencilerin başarılarının artmasıdır ve bununla ilgili birçok ampirik araştırma da bulunmaktadır (Goddard, Goddard ve Tschannen-Moran, 2007, s. 886; Goddard, Miller, Larson ve Goddard, 2010, s. 15; Vangrieken, Dochy, Raes ve Kyndt, 2015, s. 28). Ancak bu araştırmalarda öğretmenler arasında mesleki işbirliğinin öğrenci başarısı üzerinde bir etkisi olduğu ileri sürülse de bu etki doğrudan bir etkiden daha çok dolaylı bir etkidir. Çünkü öğretmenler arasındaki mesleki işbirliğinin asıl önemli etkisi öğretmenlerin öğrenme-öğretme uygulamalarını nasıl geliştireceklerini öğrenmeleri ile ilgilidir ve bu işbirliği çalışmalarının öğrencilerin başarıları üzerinde dolaylı da olsa önemli bir etkisi olabilmektedir. Bu bağlamda özellikle Batılı ülkelerde sistemli işbirliği çalışmaları yapılmakta ve bu çalışmalar ilgili kurumlarca koordine edilmektedir.

Öğretmenler arasında mesleki işbirliği genel olarak “Öğretmenlerin mesleki uygulamaları analiz etmek ve etkilemek için karşılıklı olarak birlikte çalıştıkları; öğrencilerin, ekiplerin ve okulların sonuçlarını iyileştiren sistematik bir süreç" olarak tanımlanmaktadır (DuFour, 2011, s. 7). Howland ve Picciotto'ya (2003b, s. 14-18) göre öğretmenler arasında mesleki işbirliğinin gerçek doğasını belirleyen kavramlar, öğretim ile ilgili olması, tüm pedagojik ve müfredat konularılla ilgilenmesi, öğrenmeye katılan kişilerin mesleki gelişimini teşvik etmesi, eğitim programlarını geliştirmesi ve sonunda öğrencilere yarar sağlamasıdır. Bu bağlamda öğretmen işbirliği “öğrenme etkinlikleri, ders planları, ödevler, derslerin tasarımı, değerlendirmesi ve programın gözden geçirilmesi de dâhil olmak üzere öğretim ve öğrenmenin bileşenlerini düzenli olarak tartışan iki veya daha fazla öğretmeni içeren bir pedagojidir" (Howland ve Picciotto, 2003a, s. 3).

Friend ve Cook (1990, s. 72; 1992, s. 182) kişilerarası işbirliğini, ortak bir hedef doğrultusunda çalışırken gönüllü olarak ortak karar alma süreçlerine katılan en az iki eş katılımcı arasındaki doğrudan etkileşim tarzı olarak tanımlamıştır. Yazarlar bu tanımı detaylı tanımlayıcı özellikler ile açıklığa kavuşturmuş ve öğretmen işbirliğini daha fazla açıklamak için aşağıdaki özellikleri kullanmıştır (Cook ve Friend, 1993, s. 422):

- Gönüllï olmalıdrr. Öğretmenlerin yakın bir yerde çalışması gerekebilir, ancak işbirliği yapmaları gerekmeyebilir. Bu gibi durumlarda işbirliği içinde çalışmak için kişisel bir seçim yapmak zorundadırlar. İşbirliği gönüllü olduğunda ve idari olarak zorunlu olmadığında, öğretmenler genellikle meslektaşları ile yakın ama gayri resmi, işbirliğine dayalı ortaklıklar oluştururlar.

- Eşitliğe dayanmalıdrr. İşbirliği yapan öğretmenler, bütün bireylerin katkılarının eşit değerde olduğuna inanmalıdır. Öğretmenlerin katkılarının miktarı ve niteliği büyük ölçüde değişebilir, ancak öğretmenler sunduklarının işbirlikçi çaba için ayrılmaz olduğunu kabul ederler.

- Ortak bir hedef olmalddr. Öğretmenler yalnızca hedeflerini paylaştıklarında işbirliği yaparlar. Kötü tanımlanmış hedefler üzerinde çalışıyorlarsa, istemeden farklı hedefler üzerinde çalışabilirler. $\mathrm{Bu}$ gerçekleştiğinde, işbirliği yerine genellikle iletişimsizlik ve hayal kırıklı̆ı ortaya çıkabilir.

- Kilit kararlar için ortak sorumluluk içermelidir. Her ne kadar öğretmenler işbirlikçi faaliyetlerde bulundukları zaman emeklerini bölebilseler de, her biri üstlendikleri faaliyetler hakkında temel kararlar vermede eşit birer ortaktır. Bu paylaşılan sorumluluk, öğretmenler arasında var olan eşitlik duygusunu pekiştirmektedir.

- Sonuçlar için ortak hesap verebilirliği içermelidir. Bu özellik doğrudan paylaşılan sorumluluktan kaynaklanmaktadır. Diğer bir deyişle, eğer öğretmenler kilit kararları paylaşırlarsa, bu sonuçların olumlu ya da olumsuz olup olmadığına bakılmaksızın, kararlarının sonuçlarının sorumluluğunu da paylaşmaları gerekir.

- Paylaşılan kaynaklara dayanmaktadrr. İşbirliği çabalarına katılan her öğretmen bir tür kaynağa katkıda bulunur. $\mathrm{Bu}$, bağlllğın artması ve her bir profesyonelin eşlik hissinin pekiştirilmesi etkisine sahiptir. Kaynaklar zaman, uzmanlık, alan, ekipman veya bu tür diğer varlıkları içerebilir. 
- Gelisen özelliklere sabiptir. İşbirliği, katıllımcılar arasında paylaşılan karar verme, güven ve sayg1 değerine olan inanca dayanmaktadır. Bununla birlikte, işbirlikçi faaliyetlerin başında bu unsurların bir derecesine ihtiyaç duyulurken, yeni bir işbirlikçi ilişkinin temel özellikleri olmaları gerekmez. Öğretmenler işbirliğiyle daha deneyimli hale geldikçe, ilişkileri başarılı işbirlikçi ilişkiler içinde büyüyen güven ve saygı ile karakterize edilecektir.

Öğretmenler arasında mesleki işbirliği çalışmaları, öğrencilerin öğrenmesini desteklemekte, güçlü öğrenme topluluklarında çalsşan öğretmenler kariyerlerinden daha memnun olmakta ve başarılı bir eğitimci olmak için yeterince uzun süre derste kalmaları daha olası olmaktadır (Cook ve Friend, 1993, s. 423). Uluslararası Öğretme ve Öğrenme Araştırması (Teaching and Learning International Survey-TALIS) sonuçları, işbirlikçi öğrenmeye katılan öğretmenlerin daha yenilikçi pedagojiler (örneğin, küçük gruplar halinde çalş̧mak) kullanarak rapor verdiğini, daha fazla iş doyumu elde ettiğini ve daha fazla öz yeterlilik davranışları sergilediğini göstermiştir. Finlandiya gibi eğitimde yüksek performansı olan ülkelerde, öğretmenler büyük ölçüde işbirliği yapmaktadır (OECD, 2013, s. 249). İşbirlikçi kültürlerdeki öğretmenler, kendilerine yardım edebilecek ve destekleyebilecek başka insanlar olduğunun farkına vardıkça, daha olumlu bir öğretmenlik tutumu geliştirmektedirler (Hargreaves ve O'Connor, 2018, s. 5). Ancak Yılmaz, Yoldaş ve Yangil (2004, s. 205) tarafindan yapılan araştırmada sınıf öğretmenleri "zümre öğretmenler kurulu toplantılarının sıklaştırılması ve bu toplantılardaki işbirliğinin artırılması" gerektiği yönünde görüş belirtmiştir. Bu bulgu okullarda yapılan işbirliği çalısmalarının yetersiz olduğu şeklinde yorumlanabilir.

Mesleki işbirliği çalışmalarının etkileri konusunda birçok olumlu sonuçtan bahsedilebilir. Örneğin bir sınıfin derslerine giren ya da bir okulda birlikte çalışan öğretmenlerin disiplin uygulamaları konusunda işbirliği yapması o sınıftaki ya da okuldaki istenmeyen öğrenci davranışlarını azaltabilir. Öğrenme zorluğu çeken bir öğrencinin derslerine giren farklı öğretmenlerin işbirliği yapması, o çocuğun gelişiminde çok büyük bir fark oluşturabilir. Öğretmenler arasında işbirliği uygulamaları öğrencilerin de işbirliği ve takım çalışması becerileri edinmeleri açısından önemli olabilir. Günümüzde çalışanlardan beklenen önemli özelliklerden birinin de işbirliği yapabilme ve takım çalışmasına yatkınlık becerisi olduğu düşünüldügünnde bu tip bir katkı da önemli olabilir. Sonuç olarak işbirliği çalışmaları bir kurumu, okulu ya da fakülteyi oradaki kişilerin toplamından daha etkili ve daha tatmin edici bir hale getirebilir. Ayrıca işbirliği çalışmaları kişilerin sosyal sermaye oluşturması açısından da son derece önemlidir.

Aslında öğretmen işbirliği kavramı yeni bir kavram değildir. Öğretmenlerin işbirliği davranışlarının okula, öğretmenlerin mesleki gelişimine ve öğrencilerin başarılarına olumlu katkılarının olacağı kuramsal olarak eskiden beri dile getirilmektedir. Bu anlamda diğer ülkelerde konu ile ilgili çok geniş bir alanyazın oluşmuş, hatta kavram mesleki öğrenme toplulukları ve meslektaş yardımlaşması gibi kavramlara doğru evrilmiştir. Türkiye'de okullarda işbirliğinin gerçekleşebileceği zümre öğretmenler kurulları ve sınıf ögretmenler kurulları gibi resmi uygulamalar ve bazı gayri resmi uygulamalar da vardır. Gayri resmi uygulamalara, öğretmenler arasında informal yollarla oluşan uygulamalar örnek olarak verilebilir.

Yapılan tarama ve incelemelerde "işbirliği, takım çalışması, mesleki öğrenme topluluklanı, öğrenme grupları, meslektaş dayanışması ya da yardımlaşması" gibi kavramların sık sık birbirinin yerine kullanıldığ1 belirlenmiştir. Bu kavramsal karışıklık işbirliğini, işlevsel bir tanımının yapılması ve ölçülmesi zor bir yapı haline getirmiştir. İşbirliği denildiğinde genellikle, "takım çalışması, karar alma süreçlerine katılım, dayanışma” gibi kavramlar akla gelmiştir. Bu çalışmada işbirliği kavramı, öğretmenlerin işleriyle ilgili amaçlar için yürüttükleri işbirliği eylemlerini betimleyici bir kavram olarak ele alınmıştır. Bu anlamda geliştirilen ölçek öğretmenler arasındaki işbirliği çalş̧maları konusunda öğretmenlerin tutumlarını belirleyecek şekilde kurgulanmıştır. Ölçek mesleki öğrenme toplulukları ya da geçici işbirliği biçimleri üzerine odaklanmamıştır.

Okullarda, öğretmenler arasındaki işbirliği çalışmaları konusunda diğer ülkelerde bazı ölçek geliştirme çalışmaları yapılmışıtır. Tschannen-Moran (1998b, s. 129) doktora tez çalışması kapsamında bir ölçek geliştirmiştir. Bu çalışmada okullarda işbirliği konusu "Okul kararlarında okul müdürleri ile öğretmenler arasındaki işbirliği; okul kararlarında ebeveynlerle işbirliği ve sınıf kararlarında öğretmenler arasındaki işbirliği” başlıkları altında ele alınmıştır. Tschannen-Moran (1998b, s. 130) çalışmasında, okullardaki işbirliğini karar süreçleri ekseninde ele almıştır. Çalışmada "Mesleki gelişim faaliyetlerinin planlanması; öğrencilerin davranış problemlerinin çözülmesi; mesleki gelişim ihtiyaç ve hedeflerinin belirlenmesi; öğretim yöntem ve etkinliklerinin seçilmesi; öğrenci yerleştirmelerinin belirlenmesi; öğrencilerin öğrenme problemlerinin çözülmesi; müfredat ve programların değerlendirilmesi; öğrencilerin gelişiminin velilere bildirilmesi için işlemler geliştirilmesi; kural ihlallerinde sonuçların belirlenmesi ve okul kurallarının 
belirlenmesi” gibi konularda öğretmen kurullarının bu tür kararları ne ölçüde etkilediği belirlenmeye çalısılmıştır. Bu anlamda Tschannen-Moran (1998b, s. 129) çalısmasında kullanılan ölçek tam olarak bir işbirliği ölçeği değildir.

Goddard, Miller, Larsen, Goddard, Madsen ve Schroeder (2010, s. 11) çalışmalarında "Öğretmen İşbirliği Ölçeği” geliştirmişlerdir. Ölçek "Resmi İşbirliği, Öğretimde İşbirliğinin Sıklığı ve Öğretmenlerin Öğretim Politikası Konusunda İşbirliği” olmak üzere üç alt ölçekten oluşmaktadır. Ölçekte, katılımcıların resmi işbirliği ve öğretmenlerin öğretim politikası konusunda işbirliği alt boyutlarındaki maddeler katılım ölçeği; öğretimde işbirliğinin sıklığı alt boyutlarındaki maddeler sıklı ölçeği ile belirlenmiştir.

Son yıllarda, öğretmen işbirliği ile ilgili önemli çalışmalardan biri de OECD (2013, s. 171) tarafindan yapılan TALIS çalışması kapsamında yer almaktadır. Bu araştırmada öğretmen işbirliğini ölçen bir bölüm bulunmaktadır. Bu bölüm "Değişim ve Öğretim Koordinasyonu (4 Madde) ve Mesleki İşbirliği (4 Madde)" alt boyutlarından oluşmaktadır. Mesleki İşbirliği alt boyutu ise şu maddelerden oluşmaktadır: 1) Aynı sınıfta bir ekip olarak ortaklaşa öğretme. 2) Diğer öğretmenlerin sınıflarını gözlemleme ve geri bildirimde bulunma. 3) Farklı sınıflar ve yaş grupları arasındaki ortak etkinliklere katılma (örneğin projeler). 4) Dersler arasında ev ödevi uygulamalarını tartışma ve koordine etme. Bu maddeler "Asla, Yılda Bir veya Daha Az, Yılda 2-4 kez, Yilda 5-10 kez, Ayda 1-3 kez, Haftada Bir veya Daha Fazla" seçenekleri ile yanıtlanmaktadır. $\mathrm{Bu}$ yanıt seçenekleri ile öğretmenlerin anılan davranışları hangi sıklıkta yaptıklarını belirlemeye çalısıllmaktadır.

Türkiye'de konu ile ilgili uygulamalar bulunmasına ve bazı araştırmalar (Cerit, 2009; Gümüşeli ve Eryllmaz, 2011) yapılmış olmasına rağmen hem kuramsal hem de ampirik düzeyde araştırma eksikliği gözlenmiştir. Gümüşeli ve Eryllmaz (2011, s. 19) Collaborative School Culture Survey (Gruenert, 1998) adlı ölçeği Türkçeye uyarlamışlardır. Ölçek, "İşbirlikçi Liderlik, Mesleki Gelişim, Öğretmen İşbirliği, Ortak Destek, Amaç Birliği ve Öğrenme Ortaklığı” boyutlarından oluşmaktadır.

Kelchtermans (2006, s. 222) işbirliğinin kavramsallaştırılmasında kültürün ve okul bağlamının dikkate alınması gerektiğini belirtmiştir. Bu ölçek geliştirme çalışmasının çıkış noktalarından biri de budur. Cerit (2009: 644) "Öğretmenlerin Örgütsel Güven Düzeyleri İle İşbirliği Yapma Düzeyleri Arasındaki İlişki” başlıklı çalışmasında Tschannen-Moran (2001,s . 317) tarafından geliştirilen İşbirliği Anketini kullanmış ve ankette yer alan bazı maddelerdeki eylemler Türk Eğitim Sistemi'nin merkezi yapısı ile uygun olmadığından anketten çıkarılmıştır. Bu bağlamda bu çalışmada, öğretmenlerin öğretmenler arasında mesleki işbirliğine yönelik tutumlarını belirlemede kullanılabilecek bir veri toplama aracının geliştirilmesi amaçlanmıştır.

\section{Yöntem}

\section{Çalışma Grubu}

Araştırmada ölçeğin yapı geçerliğinin belirlenmesi için yapılan açımlayıcı faktör analizi (AFA) ve doğrulayıcı faktör analizi (DFA) için iki farklı gruptan veri toplanmıştır. Veriler 2018-2019 eğitim öğretim yılında toplanmıştır. Araştırmada hem AFA hem de DFA için örneklem büyüklüğünde madde sayısının en az 10 katı kadar katılımcıya ulaşılması planlanmışır. Bu çerçevede, AFA için 273, DFA için 164 öğretmenden kullanılabilir veri toplanmıştır.

Birinci grupta 273 kişi bulunmaktadır. Bu veriler internet ortamında toplanmıştır. Birinci örneklem grubunda (AFA yapılan) yer alan öğretmenlerin \%54.6's1 kadın ( $\mathrm{n}=149), \% 45.4$ ü ise erkektir $(\mathrm{n}=124)$. Öğretmenlerin \%3.3’ü okulöncesi eğitim kurumlarında ( $\mathrm{n}=9), \% 30$ ’u ( $\mathrm{n}=82$ ) ilkokullarda, \%39.6's1 ortaokullarda ( $\mathrm{n}=108), \% 27.1$ 'i liselerde $(\mathrm{n}=74)$ görev yapmaktadır. Bu gruptaki öğretmenlerin \%48.4'ü 110 yil ( $\mathrm{n}=132), \% 33$ 'ü 11-20 yıl kıdeme ( $\mathrm{n}=90), \% 18.7$ 'si 21 yll ve üstü kıdeme ( $\mathrm{n}=51)$ sahiptir.

İkinci örneklem grubunda 164 kişi bulunmaktadır. Bu kişiler Kütahya ilinde görev yapan ve araştırmaya gönüllü olarak katılan öğretmenlerden oluşmaktadır. İkinci örneklem grubunda (DFA yapılan) yer alan öğretmenlerin \%52.4'ü kadın ( $n=86), \% 47.6$ 's1 erkektir ( $n=78)$. Öğretmenlerin \%12.8’i okulöncesi eğitim kurumlarında ( $\mathrm{n}=21), \% 25$ 'i ilkokullarda $(\mathrm{n}=41), \% 40.9$ 'u ortaokullarda $(\mathrm{n}=67), \% 21.3$ 'ü liselerde $(\mathrm{n}=35)$ görev yapmaktadır. Bu gruptaki öğretmenlerin \%42.7’si 1-10 yll ( $\mathrm{n}=70), \% 45.1$ ’i 11-20 yıl kıdeme ( $\mathrm{n}=74), \% 12.2$ 'si 21 yil ve üstü kideme (n=20) sahiptir. 


\section{Veri Toplama Aracının Geliştirilmesi}

Yapılan alanyazın taramaları, okumalar ve daha önce geliştirilen veri toplama araçları (Cook ve Friend, 1993; DuFour, 2011; Friend ve Cook, 1990, 1992; Goddard, Miller, Larsen, Goddard, Madsen ve Schroeder, 2010; Gruenert, 1998; Howland ve Picciotto, 2003a, 2003b; OECD, 2013) incelenerek ölçek, öğretmenlerin mesleki işbirliğine yönelik tutumlarını belirlemede kullanılabilecek bir veri toplama aracı olarak kurgulanmıştır. Bir tutumun boyutları olarak düşünülen "bilişsel, duyuşsal ve davranışsal" alanlar ile ilgili maddeler yazılmışıtır. Bu üç boyuta bazı ters maddeler de eklenmiştir. Yapılan çalışsmalar sonunda ilk aşamada 50 maddelik bir madde havuzu oluşturulmuştur. Bu maddeler incelenmiş, birbirine yakın anlamı olan ya da diğer maddelerin içeriğinde olduğu düşünülen maddeler elenmiştir. Bu işlemden sonra 30 maddelik bir taslak form elde edilmiştir. 30 maddeden oluşan taslak form kapsam geçerliği için uzman görüşüne sunulmuş (4'ü eğitim yönetimi, 2'si eğitim programları ve öğretim, 1'i ölçme değerlendirme alanından) ve gelen öneriler doğrultusunda ifadeler tekrar düzenlenmiştir. Daha sonra ölçek anlaşılabilirlik ve kolay yanıtlanabilirlik gibi özellikleri bakımından 10 öğretmenin görüşüne sunulmuştur. Bu görüşler de dikkate alınarak 20 maddelik bir ölçek elde edilmiş ve ölçek ön uygulama için hazır hale getirilmiştir. Beşli Likert tipi yanıt seçenekleri bulunan ölçek, "1-Hiç Katılmıyorum, 2-Katılmıyorum, 3-Orta Derecede Katıliyorum, 4-Katıllyorum ve 5-Kesinlikle Katıliyorum" seçenekleri ile yanıtlanmaktadır.

\section{Verilerin Analizi}

Öğretmenler Arasında Mesleki İşbirliğine Yönelik Tutum Ölçeğinin yapı geçerliğini belirlemede öncelikle Açımlayıcı Faktör Analizi (AFA), daha sonra da söz konusu yapının geçerli bir yapı olup olmadığının belirlenmesi için Doğrulayıcı Faktör Analizi (DFA) uygulanmıştır. Ölçeğin yapısı oluştuktan sonra dağılımın normalliği ve uç değerler incelenmiş, veri temizliği yapıldıktan sonra analizler tekrarlanmıştır. Dağılımın normalliğinin belirlenmesinde çarpıklık ve basıklık katsayılarına bakılmıştır. Bu değerlerin +1 ile -1 araladığında olduğu görülmüştür. Uç değerlerin belirlenmesinde $\mathrm{z}$ değerleri ve Mahalanobis uzaklıkları hesaplamıştır. Z değeri +3'ten büyük ve -3 'ten küçük değerler ile .01 anlamlılık düzeyine göre $\chi^{2}$ tablo değerinin üzerindeki Mahalanobis değerleri uç değerler olarak belirlenerek veri setinden çıkarılmıştır. Ölçeğin güvenirliği için madde toplam korelasyonu, Cronbach's Alfa iç tutarlık katsayısı ile alt ve üst \%27’lik grupların madde ortalama puanları incelenmiştir.

\section{Bulgular}

Bu bölümde Öğretmenler Arasında Mesleki İşbirliğine Yönelik Tutum Ölçeğinin geçerlik ve güvenirlik analizlerine ilişkin bulgulara yer verilmiştir. Ölçeğin geliştirilmesi sürecinde katıllmcılardan toplanan veriler üzerinde önce açımlayıcı ve doğrulayıcı faktör analizi, daha sonra güvenirlik analizleri yapılmışır.

\section{Açımlayıcı Faktör Analizine (AFA) İlişkin Bulgular}

Verilerin faktör analizi için uygun olup olmadı̆̆ını belirlemek için Kaiser Meyer Olkin (KMO) değeri ve Bartlett Küresellik Testi sonuçları incelemiştir. İlk analizde KMO değeri .90 ve Bartlett Küresellik Testi $\left[\chi^{2}=1115,983\right.$; sd $\left.=105 ; \mathrm{p}<.01\right]$ anlamlı olarak bulunmuştur. Bu değerler, verilerin faktörleşmeye uygun olduğunu göstermektedir (Büyüköztürk, 2014, s. 126).

Veri toplama aracının yap1 geçerliğini sınamak için öncelikle Açımlayıcı Faktör Analizi (AFA) yapılmıştır. AFA yapılırken temel bileşenler analizi uygulanmıştır. Maddelerin ölçekte kalmasında faktör yük değerlerinin .40’tan büyük olması (Şencan, 2005, s. 390) ve birden fazla faktörde yüksek yük değeri veren maddelerin faktör yükleri arasındaki farkın en az .10 olması ölçütü temel alınmıştır (Büyüköztürk, 2014, s. 125).

İlk analiz sonrasında ölçek maddelerinin özdeğeri 1'den büyük beş faktör altında toplandığ1 ancak çizgi grafiği incelendiğinde ölçeğin tek faktörlü bir yapı gösterdiği tespit edilmiştir. Buna göre faktör yük değeri .40'n altında olan üç madde (Madde 5, Madde 6, Madde 20) ve birden fazla boyutta yük değerine sahip olan iki madde (Madde 7, Madde 18) ölçekten çıkarılmıştır. Daha sonra ise iki maddenin (Madde 2, Madde 11) tek başına boyut olduğu görülmüş ve bu maddeler de ölçekten çıkarılmıştır. Ölçek tek faktörlü olarak analiz edilmiş ve maddeler çıkarıldıktan sonra 13 maddeye düşen ölçeğe yeniden AFA uygulanmıştır. Bu işlemlerin yapılması sırasında maddeler ölçekten tek tek çıkarılmış ve her defasında analiz tekrarlanmışır (Çokluk, Şekercioğlu ve Büyüköztürk, 2014: 223). Bu işlemde ölçek maddelerinin herhangi bir müdahale gerektirmeden tek faktörlü bir yapıda olduğu görülmüştür. On üç maddelik ölçek 
için KMO değeri .92 ve Barlet Küresellik Testi $\left[\chi^{2}=1135,715\right.$; sd=78; $\left.\mathrm{p}<.01\right]$ anlamlı olarak bulunmuştur. Faktör analizi sonuçları Tablo 1'de verilmiştir.

Tablo 1. Öğretmenler Arasinda Mesleki Isşbirliğine Yönelik Tutum Ölçę̆inin AFA Sonuçlar

\begin{tabular}{|c|c|}
\hline Madde & $\begin{array}{c}\text { Faktöt Yük } \\
\text { Değeri }\end{array}$ \\
\hline M1 - İşbirliği çalışmaları öğrenmenin doğasını keşfetmemize yardımcı olur. & .60 \\
\hline M2 - Öğretmenlerle yaptığım işbirliği çalışmaları mesleğime katk1 sağlar. & .75 \\
\hline M3 - Paylaşılan öğrenmeler, öğrenme sorunlarının doğasını keşfetmemize yardımcı olur. & 70 \\
\hline M4 - Okullarda işbirliği çalışmaları yapmak boşa zaman harcamaktır.* & .53 \\
\hline M5 - İşbirliği çalışmaları işlerin yapılmasını zorlaştırıyor.* & .55 \\
\hline M6 - İşbirliği çalışmaları öğretmenlerin yaratıcılığını kısıtlıyor.* & .62 \\
\hline M7 - İşbirliği, kendimi okulun bir üyesi gibi hissetmemi sağlar. & .74 \\
\hline M8 - Başkalarından bir şeyler öğrenmekten memnun olurum. & .55 \\
\hline M9 - İșbirliği çalıșmaları bir kurumdaki insanları birbirine yakınlaștırır. & .76 \\
\hline M10 - İșbirliği gerektiren çalıșmalara gönüllü olarak katılıyorum. & .53 \\
\hline M11 - İşbirliği yapınca iletişim becerilerimiz gelişiyor. & .59 \\
\hline M12 - İșbirliği çalıșmaları sayesinde yıkıcı çatıșmaları daha kolay çözebiliyoruz. & .73 \\
\hline M13 - İşbirliği yapinca okulun toplam performansı gelişiyor. & .65 \\
\hline *Ters kodlanan maddeler & ryans: $\% 41,10$ \\
\hline
\end{tabular}

Tablo 1'de de görüldüğü üzere, Öğretmenler Arasında Mesleki İşbirliğine Yönelik Tutum Ölçeğinin tek faktörlü yapısında yer alan 13 maddenin faktör yük değerleri .53 ile .76 arasında değişmektedir. Ölçeğin tek faktörlü yapısının açıkladığı varyans \% 41,10'dur.

\section{Doğrulayıcı Faktör Analizine (DFA) İlişkin Bulgular}

AFA sonucu tek faktör altında toplanan 13 maddelik Öğretmenler Arasında Mesleki İşbirliğine Yönelik Tutum Ölçeği farklı bir örneklem grubuna tekrar uygulanmıș ve elde edilen veriler ile DFA yapılmıştır. DFA sonucu elde edilen bulgular değerlendirildiğinde " $\chi 2 /$ sd oranı $95,852 / 65=1,475$ ” olarak belirlenmiştir. DFA ile hesaplanan diğer uyum iyiliği değerleri ise şöyledir: GFI=.952, AGFI=.933, $\mathrm{IFI}=.972, \mathrm{RMR}=.025, \mathrm{CFI}=.971, \mathrm{NFI}=.917$, RMSEA=.042. Bu uyum iyiliği değerlerinin tümü, Öğretmenler Arasında Mesleki İşbirliğine Yönelik Tutum Ölçeğine ait tek boyutlu ölçüm modelinin kabul edilebilir bir model olduğunu göstermektedir (Byrne, 2011; Çelik, 2009; Hair, Black, Babin ve Anderson, 2010; Tabachnick ve Fidell, 2013). Yapılan DFA sonucunda oluşan path diyagramına Şekil 1'de yer verilmiştir.

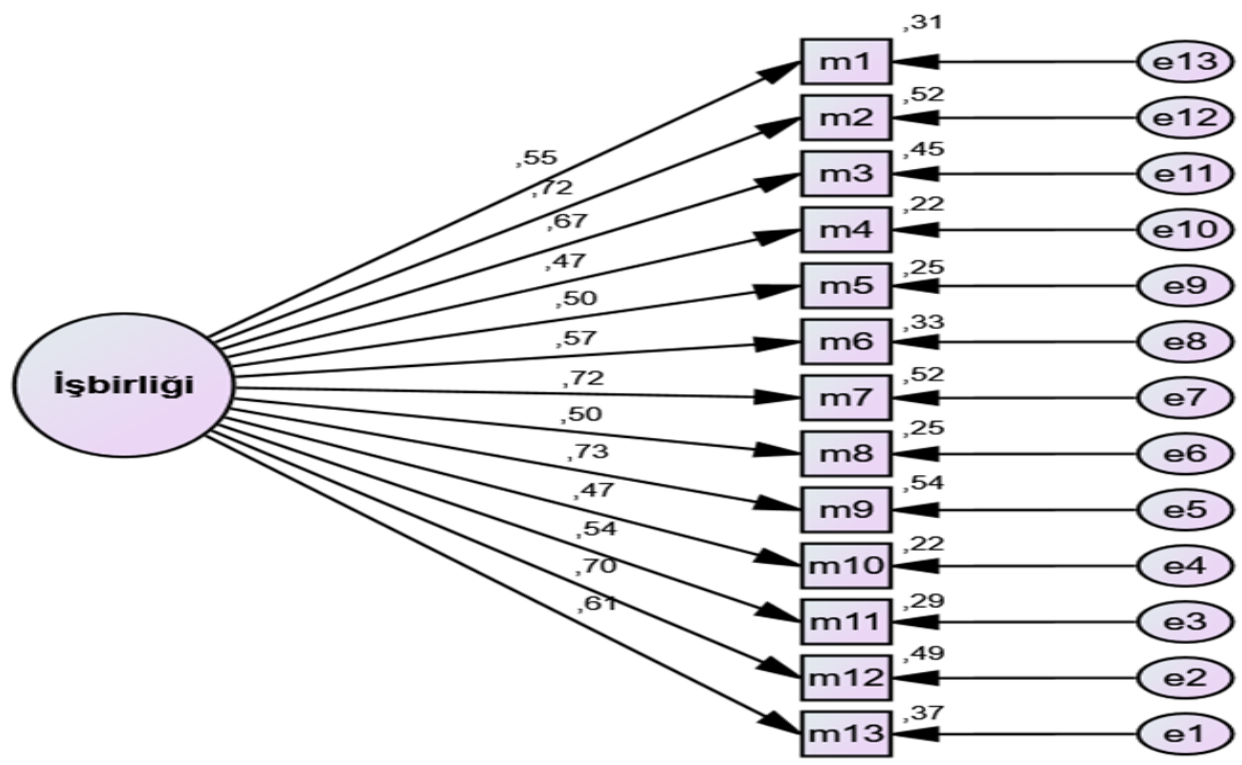

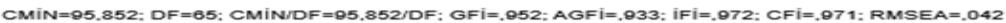

Şekil 1. Öğretmenler Arasinda Mesleki İsbirliğine Yönelik. Tutum Ölçeği Path Diyagramı 
Şekil 1'de de görüldüğü gibi Öğretmenler Arasında Mesleki İşbirlliğine Yönelik Tutum Ölçeğinde yer alan maddelerin faktör yük değerleri .47 ile .73 arasında değişmektedir.

\section{Ölçeğin Güvenirliğine İlişkin Bulgular}

Öğretmenler Arasında Mesleki İşbirliğine Yönelik Tutum Ölçeğinin güvenirliği için madde toplam korelasyonları, alt ve üst \% 27'lik grupların madde ortalama puanları arasındaki farklar ve Cronbach's Alfa iç tutarlık katsayıları incelenmiştir. Ölçeğin güvenirliğine ilişkin sonuçlar Tablo 2'de sunulmuştur.

Tablo 2. Öğretmenler Arasinda Mesleki Issbirlï̆ine Yönelik Tutum Ölçeğinin Güvenirliğine İlişkin Sonuçlar

\begin{tabular}{|c|c|c|c|c|c|c|c|}
\hline \multirow{2}{*}{$\begin{array}{c}\text { Madde } \\
\text { No }\end{array}$} & \multirow{2}{*}{$\begin{array}{c}\text { Madde Toplam } \\
\text { Korelasyonu }\end{array}$} & \multicolumn{2}{|c|}{$\begin{array}{c}\text { Alt } \% 27 \\
(n=74)\end{array}$} & \multicolumn{2}{|c|}{$\begin{array}{c}\ddot{U} s t \% 27 \\
(n=74)\end{array}$} & \multirow[b]{2}{*}{$t$} & \multirow[b]{2}{*}{$p$} \\
\hline & & $A O$ & $S$ & $A O$ & $S$ & & \\
\hline M1 & .51 & 4,04 & 0,60 & 4,91 & 0,27 & 11,427 & .00 \\
\hline M2 & .66 & 3,76 & 0,61 & 4,85 & 0,35 & 13,268 & .00 \\
\hline M3 & .62 & 3,70 & 0,63 & 4,71 & 0,65 & 9,5970 & .00 \\
\hline M4 & .46 & 3,61 & 1,00 & 4,86 & 0,53 & 9,4860 & .00 \\
\hline M5 & .47 & 3,62 & 0,92 & 4,74 & 0,62 & 8,6300 & .00 \\
\hline M6 & .54 & 3,64 & 0,86 & 4,78 & 0,41 & 10,231 & .00 \\
\hline M7 & .65 & 3,66 & 0,64 & 4,78 & 0,41 & 12,517 & .00 \\
\hline M8 & .46 & 4,23 & 0,58 & 4,93 & 0,25 & 9,4460 & .00 \\
\hline M9 & .68 & 3,80 & 0,61 & 4,97 & 0,16 & 15,861 & .00 \\
\hline M10 & .45 & 3,38 & 0,86 & 4,58 & 0,72 & 9,1260 & .00 \\
\hline M11 & .50 & 3,81 & 0,71 & 4,87 & 0,52 & 10,412 & .00 \\
\hline M12 & .65 & 3,48 & 0,81 & 4,67 & 0,55 & 10,505 & .00 \\
\hline M13 & .57 & 3,57 & 0,91 & 4,79 & 0,40 & 10,507 & .00 \\
\hline
\end{tabular}

Tablo 2'de de görüldüğü gibi ölçekte bulunan maddelerin madde-toplam korelasyonlar1 .45 ile .68 arasında değişmektedir. Madde toplam korelasyonu değerlerinin pozitif ve yüksek olması, maddelerin benzer davranışları örneklediğini ve ölçeğin iç tutarllğının yüksek olduğunu ifade etmektedir. Maddetoplam korelasyonu değeri .30 ve daha yüksek olan maddelerin kişileri iyi derecede ayırt ettiğgi ifade edilmektedir (Büyüköztürk, 2014, s. 171).

Ölçeğin güvenirlik analizi kapsamında, testin toplam puanlarına göre oluşturulan alt ve üst \% 27’lik grupların madde ortalama puanları arasındaki farklar ele alınmıştır. Yapılan analizde, tüm maddelerin alt ve üst \% 27’lik grupları arasındaki fark $\mathrm{p}<.00$ düzeyinde anlamlıdır. Gruplar arasındaki farkların anlamlı çıkması, maddelerin ölçülen davranış bakımından kişileri ayırt ettiğini göstermektedir (Büyüköztürk, 2014). Ayrıca, ölçeğin güvenirliği için Cronbach's Alfa iç tutarlık katsayısı incelenmiş ve bu katsayının .87 gibi yüksek bir değer olduğu belirlenmiştir. Hesaplanan iç tutarlık katsayısı, ölçeğin güvenirliğinin yüksek olduğunu göstermektedir.

\section{Sonuç ve Öneriler}

Bu çalışmada öğretmenler arasında mesleki işbirliği konusunda öğretmenlerin tutumlarını belirlemede kullanılabilecek geçerli ve güvenilir bir veri toplama aracının geliştirilmesi amaçlanmıştır. Bu amaçla başlangıçta 50 maddelik bir soru havuzu oluşturulmuş, yapılan incelemeler sonucunda bazı maddeler çıkarılmış, 30 maddelik bir taslak form uzman görüşüne sunulmuş ve uzman görüşü sonrasinda 30 maddelik ölçek 20 maddelik bir taslak form haline gelmiştir. Bu aşamadan sonra, 20 maddelik ölçek öğretmenlerden oluşan çalışma gruplarına uygulanmış ve elde edilen veriler üzerinden ölçeğin geçerlik ve güvenirlik analizleri yapılmıştır.

AFA sonucunda, başlangıçta ölçek maddeleri beş faktör altında toplanmıştır. Yapılan işlemler sonucunda ölçeğin, 13 maddeden oluşan tek boyutlu bir ölçek olduğu belirlenmiştir. Ölçekte yer alan maddelerin faktör yük değerleri ,53 ile ,76 arasında değişmektedir. Ölçeğin tek faktörlü yapısının tek başına açıkladığı varyans \%41,10'dur. Bu değer sosyal bilimler ya da davranış bilimleri açısından kabul edilebilir değerler arasındadır. Sosyal bilimlerde çok yüksek varyans oranlarına ulaşmak mümkün olmadığı için \%40 ile \%60 arasında değissen varyans oranları yeterli kabul edilmektedir (Büyüköztürk, 2014; Şencan, 2005; Tavşancll, 2006).

Ölçeğin, AFA sonucunda tek faktör altında toplanan 13 maddelik yapısına DFA uygulanmıştır. DFA ile hesaplanan diğer uyum iyiliği değerleri modelin geçerli bir model olduğunu göstermektedir. Böylece söz 
konusu yapının doğrulandığına karar verilmiştir. DFA’ya göre Öğretmenler Arasında Mesleki İşbirliğine Yönelik Tutum Ölçeğinde yer alan maddelerin faktör yük değerleri .47 ile .73 arasında değişmektedir.

Ölçeğin Cronbach's Alfa iç tutarlık katsayısı ,87'dir. Ölçekte yer alan maddelerin madde-toplam korelasyonları ,45 ile,68 arasında değişmekte ve maddelerin alt ve üst \% 27'lik grupları arasındaki fark anlamlidir.

Sonuç olarak Öğretmenler Arasında Mesleki İşbirliğine Yönelik Tutum Ölçeğinin nihai formu 13 maddeden oluşmakta ve "1-Hiç Katılmıyorum, 2-Katılmıorum, 3-Orta Derecede Katilıyorum, 4Katıllyorum ve 5-Kesinlikle Katılıyorum" seçenekleri ile yanıtlanmaktadır. Ölçekte bulunan 10 madde düz, 3 madde ise ters puanlanmaktadır. Ölçekten alınan puanın yükselmesi, yanıtlayan kişinin öğretmenler arasında mesleki işbirliğine yönelik tutumunun olumlu olduğu, düşmesi ise olumsuz olduğu şeklinde yorumlanmaktadır. Öğretmenler Arasında Mesleki İşbirliğine Yönelik Tutum Ölçeğinin geçerlik ve güvenirlik analizine ilişkin bulgular birlikte değerlendirildiğinde, ölçeğin öğretmenler arasında mesleki işbirliği konusunda öğretmenlerin tutumlarının ölçümünde kullanılabilecek geçerli ve güvenilir bir araç olduğu ifade edilebilir. Bu ölçek okulların örgütsel yaşamında bulunan hemen hemen bütün değişkenler ile birlikte çalışılabilecek bir konu olan işbirliği konusunu ele almıştır. Çünkü işbirliği konusu hem bağımlı hem de bağımsız değiş̧ken olarak, örgütsel yaşamdaki birçok değişken ile yakından ilgilidir.

\section{Etik Beyan}

“Öğretmenler Arasında Mesleki İşbirliğine Yönelik Tutum Ölçeğinin Geliştirilmesi” başlıklı çalısmanın yazım sürecinde bilimsel, etik ve alıntı kurallarına uyulmuş; toplanan veriler üzerinde herhangi bir tahrifat yapılmamış ve bu çalışma herhangi başka bir akademik yayın ortamına değerlendirme için gönderilmemiştir.

\section{Kaynakça}

Büyüköztürk, Ş. (2014). Sosyal bilimler için veri analizįi el kitabı. Ankara: Pegem Akademi.

Byrne, B. M. (2011). Structural equation modeling with AMOS Basic concepts, applications, and programming (Multivariate applications series). New York: Routledge.

Cerit, Y. (2009). Öğretmenlerin örgütsel güven düzeyleri ile işbirliği yapma düzeyleri arasındaki ilişki. Uludă̆ Üniversitesi Ë̈itim Fakültesi Dergisi, 22(2), 637-657.

Cook, L. ve Friend, M. (1993). Educational leadership for teacher collaboration. Program leadership for serving students with disabilities (Edt: B. S. Billingsley, D. Peterson, D. Bodkins, M. B. Hendricks). https:// files.eric.ed.gov/fulltext/ED372532.pdf.

Çelik, A. H. (2009). Yapısal eşitlik modellemesi ve bir uygulama: Genişletilmiş online alssveriş kabul modeli (Yayımlanmamış Doktora Tezi). Eskişehir Osmangazi Üniversitesi Fen Bilimleri Enstitüsü, Eskişehir.

Çokluk, Ö., Şekercioğlu, G. ve Büyüköztürk, Ş. (2014). Sosyal bilimler için çok değğskenli istatistik: SPSS ve LISREL uygulamalar (3. Baskı). Ankara: Pegem Akademi.

DuFour, R. (2011). What is a professional learning community? Educational Leadership, 61(8), 6-11.

Friend, M. ve Cook, L. (1990). Collaboration as a predictor for success in school reform. Journal of Educational and Psychological Consultation, 1(1), 69-86.

Friend, M. ve Cook, L. (1992). Interactions: Collaboration skills for school professionals. White Plains, NY: Longman.

Goddard, Y. L., Goddard, R. D. ve Tschannen-Moran, M. (2007). A theoretical and empirical investigation of teacher collaboration for school improvement and student achievement in public elementary schools. Teachers College Record, 109, 877-896.

Goddard, Y. L., Miller, R., Larsen, R., Goddard, R. D., Madsen, J. ve Schroeder, P. (2010). Connecting principal leadership, teacher collaboration, and student achievement. Paper presented at the American Education Research Association Annual Conference, Denver. May 3. https:// files.eric.ed.gov/fulltext/ED528704.pdf.

Gruenert, S. W. (1998). Development of a school culture survey. (Unpublished Digital Dissertation). University of MissouriColumbia Missouri. Retrieved from www.MLLC.org

Gümüsseli, A. İ. ve Eryllmaz, A. (2011). The measurement of collaborative school culture (CSC) on Turkish schools. New Horizons in Education, 59(2), 13-26.

Hair, J. F., Black, W. C., Babin, B. ve Anderson, R. E. (2010). Multivariate data analysis (7th Edition). Upper Saddle River, NJ: Prentice-Hall.

Hargreaves, A. ve O'Connor, M. T. (2018). Leading collaborative professionalism. East Melbourne: Centre for Strategic Education. http://www.andyhargreaves.com/uploads/5/2/9/2/5292616/seminar_series_274-april2018.pdf.

Howland, J. ve Picciotto, H. (2003a). Professional development from the inside: Teacher collaboration in the independent secondary school. http://www.picciotto.org/math-ed/teaching/collaboration.pdf

Howland, J. ve Picciotto, H. (2003b). Teacher collaboration: Professional development from the inside. http://www.picciotto.org/math-ed/teaching/collaboration-slides.pdf 
Kelchtermans, G. (2006). Teacher collaboration and collegiality as workplace conditions. A review. Zeitschrift für Pädagogik, 52(2), 220-237.

OECD (2013). TALIS 2013 Results an International Perspective on Teaching and Learning. https://www.oecd.org/education/school/talis-2013-results.htm.

Şencan, H. (2005). Sosyal ve davranıssal ölçümlerde güvenirlike ve geçerlilik. Ankara: Seçkin Yayıncılık.

Tabachnick, B. G. ve Fidell, L.S. (2013). Using multivariate statistics (6 $6^{\text {th }}$ Edition). Boston: Ally and Bacon.

Tavşancıl, E. (2006). Tutumlarn ölçülmesi ve SPSS ile veri analiz̨i (3. Baskı). Ankara: Nobel Yayın Dağıtım.

Tschannen-Moran, M. (1998b). Trust and collaboration in urban elementary schools. Unpublished Dissertation. The Ohio State University, Dissertation Abstract UMI: 9900923.

Tschannen-Moran, M. (2001). Collaboration and the need for trust. Journal of Educational Administration, 39, 308-331.

Vangrieken, K., Dochy, F., Raes, E. ve Kyndt, E. (2015). Teacher collaboration: A systematic review. Educational Research Review, 15, 17-40.

Yılmaz, K., Yoldaş, C. ve Yangil, K. (2004). Sınıf öğretmenlerinin mesleki gelişimleri ile ilgili görüşleri. Süleyman Demirel Üniversitesi Burdur Ë̆itim Fakültesi Dergisi, 5(7), 198-210.

\section{EXTENDED ABSTRACT}

The teaching profession is traditionally seen as an isolated profession, since it is usually performed isolated from the other people in class and similar settings. However, when the essence of the work is considered, it should not be forgotten that the most powerful sources of support for teachers' professional development are their colleagues. The most important point of this process is that teachers communicate with each other and share their experiences. In this context, it is mentioned that teaching should be done in cooperation, not in an isolated way, and it is stated that the cooperation of teachers on professional issues has many positive effects on school and education. The most important of these positive results is, of course, the increase in students' success and there are many empirical studies related to this (Goddard, Goddard, \& Tschannen-Moran, 2007; Goddard, Miller, Larson, \& Goddard, 2010; Vangrieken, Dochy, Raes, \& Kyndt, 2015).

The professional cooperation between teachers is generally defined as "a systematic process that teachers work reciprocally to analyze and influence the professional practices; that improves the outcomes of students, teams, and schools" (DuFour, 2011). According to Howland and Picciotto (2003b), the concepts that determine the true nature of the professional collaboration between teachers are related to teaching, interested in all pedagogical and curriculum issues, encouraging the professional development of the learning participants, developing the educational programs, and ultimately benefiting for students. In this context, the teacher collaboration is "a pedagogy involving two or more teachers who regularly discuss the components of teaching and learning, including learning activities, lesson plans, assignments, course design, assessment, and program review" (Howland, \& Picciotto, 2003a).

The studies of professional collaboration between teachers support students' learning, the teachers who work in strong learning communities are more satisfied with their careers and are more likely to stay in class for long enough to become a successful educator (Cook, \& Friend, 1993). The results of the Teaching and Learning International Survey-TALIS showed that the teachers who participate in cooperative learning report using more innovative pedagogies (e.g. working in small groups), achieve greater job satisfaction and exhibit more self-efficacy behaviors. In countries with high performance in education, such as Finland, teachers collaborate greatly (OECD, 2013). Teachers in collaborative cultures develop a more positive teaching attitude as they become aware that there are other people who can help and support those (Hargreaves, \& O’Connor, 2018).

Many positive results can be mentioned about the effects of the professional collaboration. For example, the collaboration of the disciplinary practices by teachers who attend the courses of a class or work together in a school can reduce the unwanted student behaviors in that class or school. Collaboration of the different teachers attending the courses of a student who has learning difficulties can make a huge difference in the development of that child. The practices of professional collaboration between teachers can be important for students in terms of acquiring the collaboration and teamwork skills. This type of contribution may also be important given that one of the important features expected from the employees today is the ability to cooperate and the tendency to teamwork. As a result, the collaboration studies can make an institution, school or faculty more effective and more satisfying than the total number of people there. Moreover, the collaboration studies are extremely important in terms of creating social capital for people. 
Although there are applications related to the issue in Turkey and made some researches (Cerit, 2009; Gümüşeli, \& Eryllmaz, 2011), it was observed a lack of research on both theoretical and empirical levels. In this context, in this study, it was aimed to develop a data collection tool that can be used to determine the teachers' attitudes about the professional collaboration between teachers.

For this purpose, initially a pool of 50 items was created, as a result of the examinations some of the items were removed, a 30-item draft form was presented to the expert's opinion and after the expert's opinion the 30 -item scale became a 20 -item draft form. After this stage, the 20-item scale was applied to the study groups consisting of teachers and the validity and reliability analyzes of the scale were performed on the obtained data.

Data were collected from two different groups for the exploratory factor analysis (EFA) and the confirmatory factor analysis (CFA) to determine the construct validity of the scale. There were 273 people in the first working group and 164 people in the second working group consisting of pre-school, primary, secondary and high school teachers.

As a result of the EFA, the scale items were initially collected under five factors. As a result of the transactions it was determined that the scale was a one-dimensional scale consisting of 13 items. Factor load values of the items in the scale are ranging from .53 to .76. The explained variance of the single factor structure of the scale is $41.10 \%$. This value is between the acceptable values in terms of the social sciences or the behavioral sciences. Since it is not possible to reach very high variance rates in the social sciences, variance rates between $40 \%$ and $60 \%$ are considered sufficient (Büyüköztürk, 2014; Şencan, 2005; Tavşanc1, 2006).

CFA was applied to the 13-item structure of the scale, which was collected under one factor as a result of EFA. Other goodness of fit values $(\chi 2 / \mathrm{sd}=1,475, \mathrm{GFI}=.952, \mathrm{AGFI}=.933, \mathrm{IFI}=.972, \mathrm{RMR}=.025$, $\mathrm{CFI}=.971, \mathrm{NFI}=.917, \mathrm{RMSEA}=.042)$ calculated by $\mathrm{CFA}$ indicate that the model is a valid model. Thus, it was decided that the structure in question was confirmed. According to the CFA, the factor load values of the items in the Attitude Scale for the Professional Collaboration between Teachers are ranging from .47 to .73 .

Cronbach's Alpha internal consistency coefficient of the scale is .87. Item-total correlations of the items in the scale are ranging from .45 to .68 and the difference between the upper and lower $27 \%$ groups of the items is significant. As a result, a valid and reliable data collection tool that can be used to determine the attitudes of teachers on professional collaboration between teachers was developed. 